\title{
As Vantagens do Empreendedorismo Versus a Dependência do Assistencialismo Filantropia: Por que Estimular o Empreendedor e Evitar o Assistido?
}

\section{The Advantages of Entrepreneurship Versus the dependence on Philanthropy: Why Encourage Entrepreneur and Avoid The Assisted?}

\author{
Recebido: 10/03/2015 - Aprovado: 22/05/2015 - Publicado: 30/06/2015 \\ Processo de Avaliação: Double Blind Review
}

\author{
João Pinheiro de Barros Neto ${ }^{1}$ \\ Doutor em Ciências Sociais-Relações Internacionais \\ Mestre em Administração \\ Pontifícia Universidade Católica de São Paulo \\ professorbarros@hotmail.com
}

\begin{abstract}
Resumo - O presente artigo teórico-empírico explica e reflete de forma contextualizada, como o empreendedorismo e não o assistencialismo pode ajudar a resolver grande parte dos problemas econômicos e sociais atuais. Com dados e informações de pesquisa bibliográficas e de organismos nacionais e internacionais são apresentadas as vantagens, para todas as partes interessadas, em se substituir o assistencialismo pelo empreendedorismo. O artigo mostra, de maneira objetiva, o equívoco de se adotar políticas e ações assistencialistas em detrimento do fomento ao empreendedorismo. É proposta uma metodologia para implantar projetos empreendedores e obter resultados e conclui com a importância de uma mudança paradigmática relativa à adoção do empreendedorismo com uma visão de abundância ao invés de escassez.
\end{abstract}

Palavras-chave: empreendedorismo, assistencialismo, responsabilidade social.

Abstract - This present theoretical and empirical paper explains reflects, in context, such as entrepreneurship and not the philanthropy may help to resolve most of the current economic and social problems. Based on data and bibliographic research information, national and international organizations, the advantages are presented to all stakeholders, replacing the philanthropy by entrepreneurship. The article shows, objectively, the misunderstanding of adopting policies and actions of philanthropy at the expense of fostering entrepreneurship. A methodology is proposed to implement social projects in order to get results and concludes with the importance of a paradigm shift on the adoption of entrepreneurship with a vision of abundance rather than scarcity.

\footnotetext{
1 Autor para correspondência: Pontifícia Universidade Católica de São Paulo, Rua Monte Alegre, 984, Perdizes, São Paulo, SP, Brasil - CEP 05014-901.
} 
Keywords: entrepreneurship, welfare, social responsibility.

\section{INTRODUÇÃO}

Desde que começamos a construir nossas próprias ferramentas para sobreviver, lá estava presente o perfil empreendedor característico de toda a humanidade que com o passar do tempo só evoluiu passando pelo desenvolvimento da agricultura, pelas civilizações antigas, pela linha de montagem do automóvel de Henry Ford, até os incríveis desenvolvimentos tecnológicos que estão hoje presentes atualmente no nosso cotidiano e que, muitas vezes, não percebemos.

$\mathrm{O}$ que vemos historicamente é o ser humano naturalmente empreendedor, realizador, conquistador, que cria suas próprias soluções, sem necessidade de assistencialismo, pois para vencer é necessário buscar a vitória. É como diz um velho ditado africano: "enquanto reza, corra". Logo, pode haver duas razões para muitas pessoas não obterem sucesso ao empreender: não acreditar na possibilidade ou não estar motivado.

A diferença é que antes se empreendia sem nenhum cuidado, nem atenção, pois o que importava era empreender, realizar. Atualmente chegamos a um limite e à premissa de que é necessário o empreendedor ser socialmente responsável, portanto desenvolver seu negócio sem esgotar os recursos humanos e materiais que utiliza.

O mundo está repleto de oportunidades empreendedoras com responsabilidade social que, se bem aproveitadas, não representam apenas a chance de se fazer o bem, mas também de se fazer dinheiro, gerar riquezas e produzir desenvolvimento resolvendo problemas que trarão resultados para toda a sociedade.

É preciso apenas entender que é possível fazer as coisas da forma correta com lucro e estar atento às oportunidades que estão em todos os lugares. Com certeza quando o empreendedor age com responsabilidade social, abrem-se mais oportunidades e, portanto, prescinde do assistencialismo. Por exemplo, um terço da população mundial em plena segunda década do século XXI ainda não tem acesso à energia elétrica. Estamos falando de um mercado consumidor de pelo menos dois bilhões de pessoas ávidas por fontes alternativas de energia limpas e baratas. 


\section{METODOLOGIA}

$\mathrm{O}$ artigo objetiva explicar a relação da responsabilidade social com o empreendedorismo e refletir como o empreendedorismo e a responsabilidade social podem ajudar a resolver grande parte dos problemas atuais econômicos e sociais justificando evitar o equívoco de políticas e ações assistencialistas por pura filantropia.

Assim, inicialmente se realizou uma pesquisa bibliográfica com base em material já elaborado (GIL, 2002), constituído principalmente de livros e artigos científicos e uma pesquisa documental em relatórios, pesquisas, papers e resumos de instituições nacionais e internacionais.

\section{EMPREENDEDORISMO COMO VETOR ECONÔMICO}

O empreendedorismo é, indiscutivelmente, um importante vetor de progresso econômico e desenvolvimento social, acelerador de inovações, gerador de empregos e renda, impulsionador do aumento de produtividade e do crescimento. Observa-se que o empreendedorismo precisa se pautar pela filosofia da responsabilidade social porque, do contrário, o motor do desenvolvimento pode se transformar em uma máquina de explorar e consumir recursos indiscriminadamente.

Uma pesquisa realizada em 2012 pela Global Entrepreneurship Monitor (GEM) em cinquenta e quatro países identificou que no Brasil há cerca de 27 milhões de empreendedores que são responsáveis por mais de 60 milhões de empregos formais e informais, ou seja, mais de $75 \%$ da massa de trabalhadores em atividade.

É o empreendedorismo que está transformando a China, país número um em quantidade de empreendedores com 370 milhões, segundo a pesquisa GEM, numa potência mundial. Também foi graças ao empreendedorismo que os Estados Unidos viraram e se mantêm como uma nação rica, poderosa e hegemônica.

Não há como políticas assistencialistas ou pura filantropia venham a produzir empregos em um número suficiente para dar um nível de vida razoável a todas as pessoas, até porque a quantidade de empregos vem na verdade diminuindo. A única solução é o empreendedorismo, cada ser humano criar sua própria fonte de renda e ainda empregar outros.

O Global Entrepreneurship and the Successful Growth Strategies of Early-Stage Companies foi um estudo feito em 2011 pelo Fórum Econômico Mundial e pela 
Universidade de Stanford $^{2}$ e confirmou a ideia do empreendedorismo de alto impacto, ou seja, que há poucos empreendimentos que geram enorme impacto (tabela 1).

\begin{tabular}{|c|c|c|c|}
\hline & \multicolumn{3}{|c|}{ REVENUE CREATION } \\
\hline & \multicolumn{3}{|c|}{ AS $\%$ OF TOTAL REVENUE CREATED } \\
\hline & $\begin{array}{l}\text { TOP } 1 \% \\
\text { of Companies }\end{array}$ & $\begin{array}{l}\text { TOP 5\% } \\
\text { of Companies }\end{array}$ & $\begin{array}{l}\text { TOP } 10 \% \\
\text { of Companios }\end{array}$ \\
\hline United Kingdom & 63 & 87 & 94 \\
\hline France & 44 & 74 & 86 \\
\hline Italy & 42 & 70 & 83 \\
\hline Spain & 39 & 64 & 76 \\
\hline Belgium & 47 & 76 & 89 \\
\hline Sweden & 41 & 66 & 90 \\
\hline Norway & 26 & 60 & 79 \\
\hline Finland & 30 & 67 & 84 \\
\hline Japan & 29 & 54 & 69 \\
\hline South Korea & 26 & 51 & 66 \\
\hline Total & 44 & 72 & 84 \\
\hline
\end{tabular}

\begin{tabular}{|c|c|c|}
\hline \multicolumn{3}{|c|}{ JOB CREATION } \\
\hline \multicolumn{3}{|c|}{ AS $\%$ OF TOTAL JOBS CREATED } \\
\hline $\begin{array}{l}\text { TOP } 1 \% \\
\text { of Companies }\end{array}$ & $\begin{array}{l}\text { TOP 5\% } \\
\text { of Companies }\end{array}$ & $\begin{array}{l}\text { TOP } 10 \% \\
\text { of Companies }\end{array}$ \\
\hline 46 & 73 & 85 \\
\hline 42 & 68 & 81 \\
\hline 43 & 68 & 81 \\
\hline 33 & 61 & 75 \\
\hline 26 & 53 & 69 \\
\hline 40 & 67 & 82 \\
\hline 33 & 66 & 84 \\
\hline 33 & 68 & 84 \\
\hline 47 & 70 & 82 \\
\hline 25 & 52 & 69 \\
\hline 40 & 67 & 80 \\
\hline
\end{tabular}

Tabela 1: Criação de emprego e renda pelos empreendedores de alto impacto (Fonte: World Economic Forum, 2011, p. 63).

De fato, a pesquisa mostrou que $1 \%$ das 380.000 empresas pesquisadas em dez países contribui com $44 \%$ da renda gerada e $40 \%$ do total de empregos e que $5 \%$ dessas empresas geram $67 \%$ dos postos de trabalho e $72 \%$ das receitas totais.

Independente do impacto gerado pelos empreendedores na geração de renda e empregos diretos que criam, é importante também considerar os desdobramentos e sua influência no sistema econômico e social com seus exemplos de coragem, iniciativa e transformação, bem como quando eles se tornam estimuladores e até mesmo investidores de novos empreendimentos. Nesse sentido, toda e qualquer iniciativa empreendedora se reveste de significado social.

No Brasil, a Endeavor, uma organização sem fins lucrativos, trabalha com esse conceito de empreendedorismo de alto impacto e oferece capital e uma rede de

\footnotetext{
${ }^{2}$ Este estudo completo com 380 páginas está disponível para download gratuito no link indicado a seguir: http://www3.weforum.org/docs/WEF_Entrepreneurship_Report_2011.pdf
} 
mentores e de conexões para novos empreendedores com potencial de gerar grande impacto.

Segundo Linda Rottenberg, fundadora da Endeavor, em entrevista concedida à HSM Management (STANLEY, 2012), a organização já avaliou 30 mil candidatos, dos quais foram selecionados 650 empreendedores de 400 companhias. Ainda de acordo com Rottenberg (2011) esses "empreendedores geraram receitas de US\$ 5 bilhões e criaram 180 mil postos de trabalho de alta qualidade".

Logo, destaca-se a relevância em reforçar a importância do empreendedor que atua com responsabilidade social na construção de um mundo melhor. Se o negócio for de alto impacto, então os valores e princípios éticos praticados e disseminados pela organização também exercerão grande influência no ambiente e nos públicos alcançados pelo empreendimento.

Mesmo que o negócio seja de baixo impacto, influenciará alguém, que influenciará outro e assim o ciclo virtuoso, de baixo ou de alto impacto continuará construindo um futuro mais promissor.

A competência empreendedora é uma característica cada vez mais exigida no mercado, pois antes se precisava de pessoas e trabalhadores operacionais, mas hoje, na sociedade do conhecimento só têm espaço aqueles que colaboram com ideias e ao mesmo tempo têm a capacidade de levá-las à realização. Essa capacidade de executar, de fazer acontecer, levou Ram Charam e Larry Bossidy (2005) a escreverem um livro sobre a importância crucial da execução para o sucesso dos negócios.

Marcus Buckingham e Donald Clinton (2006) defendem que a maioria das pessoas tem um potencial inexplorado e que desconhece os próprios talentos, sendo essa uma barreira que a impede de descobrir o que pode extrair de melhor de si mesma. Realmente, esta é história recorrente que vejo e ouço ao interagir com alunos de 18 a 70 anos, pois boa parte não faz ideia dos seus talentos verdadeiros e está passando ou já passou a vida fazendo coisas que não gosta ou num emprego em que não tem a oportunidade de fazer aquilo que faz de melhor.

Ken Robinson (2010) afirma que todos nascem com talentos enormes que, a exemplo de um mineral, precisa ser extraído, mas que as pessoas não sabem extrair seu verdadeiro talento porque o sistema educacional funciona erroneamente, pois não estimula as pessoas a pensar diferente. 
Esse quadro é preocupante, pois o mundo em que vivemos exige respostas rápidas, inovação, criatividade, liderança e empreendedorismo em níveis nunca antes tão demandados. A sociedade e o meio ambiente vêm mudando rapidamente e deixando as organizações em um beco sem saída. Chegou a um ponto que não é mais possível explorar quer a sociedade quer o ambiente para extrair os recursos necessários à produção sem pagar a conta como era feito antes, quando os recursos eram abundantes e a sociedade ignorava os seus direitos.

É o espírito empreendedor natural do ser humano que permite trazer à realidade algo que não estava disponível antes, todos os empreendimentos e o desenvolvimento social vêm da força empreendedora. A questão-chave agora é que não podemos mais empreender sem considerar os limites e exigências tanto sociais como ambientais.

Uma experiência emblemática é a do Grameen Bank, também conhecido como o Banco dos Pobres. No ano de 1976, o economista e empreendedor social Muhammad Yunus (2008) criou um conceito inovador que veio completar a estrutura do capitalismo, a empresa social. Ele estava inconformado com a situação dos pobres em seu país, Bangladesh, por isso criou um banco baseado em microcréditos para solucionar um dos maiores problemas enfrentados pelos pequenos e pobres produtores independentes locais. Como não tinham acesso ao sistema bancário formal, não tinham acesso a crédito e recorriam a agiotas, virando reféns das exorbitantes taxas de juros que pagavam e inviabilizavam o crescimento dos respectivos negócios e a própria independência financeira.

Muhammad Yunus (2008) identificou uma oportunidade empreendedora naquela situação de exploração dos mais humildes, mudou a vida de milhares de pessoas, melhorou as condições sociais de significativa parte das comunidades em que atuava, apenas porque viu naquelas pessoas capacidade empreendedora e valores como confiança, respeito pelo outro e responsabilidade na hora de pagar um empréstimo.

Outros exemplos muito interessantes são apresentados por Prahalad (2010) que defende que precisamos deixar de pensar nos pobres como vítimas ou como um problema. Para ele, sustentado pelos casos que são discutidos, os pobres, como qualquer ser humano, são empreendedores, porém, devido às dificuldades que enfrentam, devido à pobreza são até mais criativos e resilientes e, como consumidores, são também mais conscientes do valor. 
Assim, se mudarmos nossa visão e entendermos todo ser humano como alguém naturalmente empreendedor e capaz de assumir comportamentos socialmente responsáveis, um mundo de oportunidades completamente novo se abrirá e problemas antes considerados insolúveis passarão a ter possibilidades de solução.

\section{EMPREENDEDORISMO SUSTENTÁVEL}

Sustentabilidade já é o negócio do presente e não pode ser tratada como um projeto isolado, mas deve estar no centro da estratégia de negócio. Isto, porém, não significa que é algo complicado, como geralmente se imagina quando falamos em estratégia. Na verdade, é mais questão de filosofia e atitude que de tecnologia ou metodologias complexas.

A sustentabilidade implica em inovar para servir melhor às pessoas e atender a suas necessidades de maneira mais eficiente, unindo inovação com o serviço à sociedade. Isso significa que para um empreendimento ser sustentável de verdade precisa engajar todas as partes interessadas, principalmente os colaboradores, os fornecedores e as lideranças sociais.

As gerações passadas nem se davam conta da importância da sustentabilidade, depois veio um período em que a ideia de sustentabilidade era uma questão financeira, pois o mote era economizar luz ou água para poupar dinheiro com o intuito de gastar com outras coisas. Somente com a crise do petróleo nas décadas finais do século passado é que surgiu a percepção de escassez e da necessidade de comportamentos sustentáveis por questão de sobrevivência da humanidade e do próprio planeta.

Nesse contexto em que a sustentabilidade passou a ser uma exigência da sociedade, as empresas necessitam estar atentas.

Para isso, mesmo quando tiver que tomar decisões rápidas, nunca deve fazê-lo de forma superficial, mas sempre colocar a sustentabilidade como fundamento básico do processo decisório. Isto significa assumir a complexidade da questão e entender que não existem fórmulas prontas e acabadas de sucesso. O importante é colocar a sustentabilidade como objetivo e correr atrás dessa meta em todas as ações e projetos da organização: resultados econômicos, sociais e ambientais.

Philip Kotler e Nancy Lee (2005) defendem e apresentam vários casos, fatos e dados que demonstram que fazer o bem não só faz bem, como é bom para os negócios. 
Eles apontam vários benefícios para empresas que adotam o triple-bottom-line, ou seja, buscam consistentemente e de maneira estratégica resultados econômicos, ambientais e sociais. Dentre os benefícios, apontam os que seguem:

a. Aumento de vendas e de participação de mercado.

b. Fortalecimento do posicionamento de marca.

c. Intensificação da imagem da influência corporativa.

d. Aumento da habilidade organizacional para atrair, motivar e manter empregados e talentos.

e. Redução de custos operacionais.

f. Maior atração de investidores e simpatia dos analistas financeiros.

Infelizmente ainda existem algumas coisas que dificultam o empreendedorismo com responsabilidade social como o fato de algumas pessoas objetivarem levar vantagem nas relações ou outras ideias pré-concebidas sobre o ser humano e ignorância a respeito do impacto de nossas ações no planeta e nas demais pessoas que vivem conosco.

Mas para isso é preciso criar um ambiente que permita que as ideias possam ser criadas e concretizadas com ética e responsabilidade. A liderança tem que ser resiliente, capaz de provocar, comunicar e demonstrar senso de oportunidade, pois os grandes problemas do mundo não estão sendo resolvidos por governos nem por estados, mas por empreendedores com senso de responsabilidade social.

Nesse sentido, o indiano Amartya Sen (2000), prêmio Nobel de economia em 1998 e um dos inventores do IDH - índice de desenvolvimento humano - lançou uma nova visão econômica baseada em liberdades.

Segundo Sen (2000, p.10), o desenvolvimento "consiste na eliminação de privações de liberdade que limitam as escolhas e as oportunidades das pessoas de exercer ponderadamente sua condição de agente" e continua afirmando que com oportunidades "sociais adequadas, os indivíduos podem efetivamente moldar seu próprio destino e ajudar uns aos outros" (idem, ibidem, p. 26). Portanto, de acordo com Sem (2000) ao prover os indivíduos de condições básicas iguais para que eles exerçam com liberdade seu papel de empreendedor. 
Assim, quando falamos em responsabilidade social, estamos pensando em uma sociedade melhor, com igualdade de oportunidades e incluindo também o conceito de sustentabilidade que preconiza produtos e serviços de acordo com as expectativas dos consumidores e geração de valor econômico, social e ambiental. Nesse sentido, empreendedores e empresas têm grande responsabilidade na criação do futuro que desejamos.

\section{COMO TRANSFORMAR PROJETOS EMPREENDEDORES EM RESULTADOS: UMA VISÃO DE ABUNDÂNCIA}

Boas intenções não são nada se não forem implantadas e trouxerem resultados e a única maneira de fazer isso é implantar a responsabilidade social por meio de projetos. Mas não é só isso. É necessário também gerenciá-los para que eles sejam bem executados e gerem vantagem competitiva para o empreendedor ou para a organização patrocinadora.

O projeto nada mais é que uma ferramenta que estabelece uma disciplina para que tudo seja feito da forma mais otimizada possível, ou seja, é estruturar uma ideia para que sua concretização cumpra prazos, metas e que traga resultados satisfatórios à organização e à sociedade. Na vida real, os projetos, assim como o planejamento, dificilmente são realizados $100 \%$ igual ao previsto, pois sempre há desvios de rumo, variáveis não consideradas, eventos inesperados e outros. Mas, sem um projeto, a possibilidade do fracasso é muito maior, assim como o seu risco.

Assim, não há opção, se quiser que algo funcione bem tem que ter um bom projeto, portanto, elaborar e gerenciar os projetos adequadamente são os passos mais importantes para garantir o sucesso da realização das ideias e iniciativas do empreendedor, não só na área de responsabilidade social, mas também na área empresarial e de negócios.

A definição mais comum de projeto é que ele é algo temporário e único, portanto, o contrário da rotina, uma vez que esta é algo fazemos repetidas vezes. Por exemplo, quando uma tarefa é rotineira, nós a repetimos sempre da mesma forma e vamos nos tornando mais rápidos, mais hábeis, mais precisos na sua realização e passamos a fazer aquilo de forma automática. 
A única forma consistente de implantar a responsabilidade social é por meio de projetos que vão permitir que a organização alcance um novo nível competitividade, por meio da prática efetiva da responsabilidade social. Se o empreendedor não gerenciá-los, esses projetos não vão ser bem implantados, não vão produzir resultados e não vão gerar a vantagem competitiva esperada.

Na maior parte das vezes o problema não está no projeto de responsabilidade social, mas na gestão do projeto, pois não fazer a sua gestão aumenta a probabilidade de lentidão da implantação, da corrupção, de serviços mal executados e outros problemas.

A questão não é fazer o bem pelo bem, mas fazer o bem de maneira sustentável e isto só vai acontecer se negócio e responsabilidade social estiverem alinhados, do contrário é filantropia ou caridade, que também são importantes, mas não resolvem problemas, apenas trazem algum conforto momentâneo.

Não obstante, destacamos a necessidade de os empreendedores se qualificarem na gestão de projetos, estarem atentos e sensíveis às mudanças que se apresentem no contexto em que atuam, evitando que seus projetos de responsabilidade social produzam resultados pífios, extrapolação de prazos, emprego de mais recursos que os necessários e outros prejuízos que contrariam toda a lógica da responsabilidade social.

Vivemos nos digladiando porque temos a capacidade de acumular coisas, o que alimenta nossa ganância, que é reforçada pela escassez. A lógica é cruel - se os recursos e as coisas são limitados e eu posso acumulá-los, então, guardo cada vez mais e, se necessário, até privando os outros de coisas que não preciso, sem o menor constrangimento. Enquanto permanecer esse paradigma da escassez e do acúmulo, continuaremos sendo egoístas e resistindo a uma postura mais solidária e socialmente responsável.

Essa lógica tem prevalecido por séculos, mas recentemente Diamandis e Kotler (2012) criaram a teoria da abundância, segundo a qual, em apenas uma geração, a humanidade será capaz de oferecer produtos e serviços a todos que os necessitem ou desejem, pois segundo eles, estamos entrando em uma época na qual a tecnologia trouxe o potencial de melhorar significativamente o padrão de vida de todas as pessoas que habitam a Terra.

A princípio pode parecer que os autores estão sendo otimistas em excesso, porém, a teoria da abundância não se refere a uma vida de luxos e excessos para todos, 
mas sim à criação de um mundo no qual todos possam sonhar e empreender, no qual todos terão suas necessidades básicas satisfeitas.

Daí a importância da teoria da abundância, que nos permite prever um futuro melhor fundamentado nos progressos da ciência e da tecnologia em direção a uma sociedade sustentável e justa. Essa teoria apresenta certa semelhança com a teoria da hierarquia de necessidades de Maslow (1954), mas tem apenas três níveis.

No primeiro nível da pirâmide da abundância estão as condições elementares para a sobrevivência, como água, comida, moradia. No segundo, localizam-se os catalisadores do desenvolvimento, como energia, educação, comunicação, informação. Por fim, no terceiro e último nível estão a liberdade e a saúde, condições necessárias para que qualquer pessoa possa empreender e oferecer sua contribuição à sociedade.

De fato, estamos testemunhando, tanto no Brasil quanto no mundo, que o acesso cada vez maior e mais fácil às tecnologias da informação - TI - e às redes sociais, somado a uma perspectiva econômica voltada para o social, multiplicam as oportunidades empreendedoras por todo o mercado global.

Um bom exemplo, dentre outros citados por Prahalad (2010), é o da Hindustan Lever, subsidiária da Unilever na Índia, que focou no entendimento das aspirações e no comportamento de compra dos consumidores emergentes, dirigiu-se a eles com a metodologia e as respostas adequadas e com isso conseguiu atender uma das populações mais pobres do mundo e ainda obter lucros.

De fato, os estudos de caso apresentados por Prahalad (2010) mostram que é possível fazer negócios até em países emergentes com responsabilidade social, de tal forma que empresa e cliente prosperem e, com isso, ajudem a sociedade e demais partes interessadas a se desenvolverem também.

Se o empreendedor não sabe por onde começar suas ações de responsabilidade social, não precisa pensar em ações muito complexas capazes de mudar o mundo de uma hora para outra, até porque isto não existe. O melhor é começar de imediato, fazendo o que é possível fazer, porque o bem atrai o bem.

\section{EMPREENDEDORISMO E NÃO ASSISTENCIALISMO}

Não devemos confundir assistencialismo com responsabilidade social. De maneira bem simples, assistencialismo, que não se confunde com ajuda humanitária em 
casos de catástrofes, é dar o peixe já frito ou assado a quem tem fome. Responsabilidade social tem mais a ver com ensinar a quem tem fome pescar e cozinhar o peixe para se virar sozinho sempre que tiver fome. Assistencialismo cria dependência e responsabilidade social dá independência.

Claro que no primeiro momento o assistencialismo se justifica para não deixar alguém morrer de fome, mas no momento seguinte a abordagem deve ser a de fazer a pessoa exercer seus dons naturais para empreender e recuperar a dignidade característica de todo ser humano.

O caso do Banco Palmas (MOUR, 2011), por meio do exemplo do Banco Palmas, demonstra que as pessoas têm capacidade nata de saírem da condição de pobreza se tiverem condições justas de concorrer pelas oportunidades. O Banco Palmas é uma iniciativa de socioeconomia solidária do empreendedor social Joaquim Melo no Conjunto Palmeira, um bairro popular da periferia de Fortaleza no estado do Ceará, com 32 mil moradores. Joaquim, líder comunitário, passou anos lutando para levar água, eletricidade, esgoto, asfalto e outros serviços públicos básicos para seu bairro extremanente pobre. Quando conseguiu, as pessoas começaram a sair do bairro porque não tinham condição de pagar suas contas e estavam indo ainda mais para a periferia. Ou seja, a prefeitura não conseguia tirá-los nem da miséria para a pobreza, por mais assistencialismo e programas de bolsas que ofereciam. Faltavam às pessoas autoestima e dignidade para cuidar de si mesmas e dos seus.

Então, conforme Yunnus (2008), Melo lutou até contra o Banco Central do Brasil para fundar um banco social com moeda própria que emprestasse dinheiro a quem quisesse empreeender. Apesar de as quantias serem irrisórias para os padrões capitalistas e em uma moeda que só tem valor no próprio bairro, ele conseguiu transformar uma comunidade decadente e miserável em uma forte economia emergente composta por empreendedores que sustentam a si mesmos e seus familiares.

Nessa conjuntura, o assistencialismo só piora as condições estruturais, mas infelizmente os países ricos, por questões escusas, peso na consciência e culpa mesmo, continuam a reproduzir o modelo da dependência ao mandar milhões de dólares anualmente em caridade e filantropia, quando na verdade deveriam era capacitar e tornar as pessoas independentes. Mas parece que é mais lucrativo continuar comprando 
matérias-primas baratas, reprocessá-las e vendê-las a preço de ouro nos mercados desenvolvidos.

Mesmo o assistencialismo bem intencionado precisa ser substituído pelo empreendedorismo socialmente responsável, se quisermos realmente resolver os complexos problemas que hoje a humanidade enfrenta. Uma rápida análise dos indicadores econômicos e sociais dos Estados Unidos, da Inglaterra, da França, da Austrália, do Japão e mais recentemente também de Cingapura e da Coréia do Sul permite constatar que todos esses países são desenvolvidos, não por causa de uma cultura assistencialista, por receber ajuda dos outros, mas por um comportamento empreendedor de tentar resolver seus problemas por conta própria e por séculos de produção e livre comércio.

Os países que não têm essa cultura de liberdade empreeendedora são os países que hoje sofrem com economias debilitadas e regimes autoritários, única maneira de manter o cidadão alienado de seu potencial empreendedor.

Há evidências contundentes de que esmolas, geralmente, não tiram pessoas da pobreza, portanto, em médio e longo prazo não ajudam, apenas criam mais dependência e acabam com a dignidade que ainda resta nas pessoas. Segundo dados disponíveis no site do World Bank Group, entre 1970 e 2000 a África como um todo recebeu 400 bilhões de dólares em doações.

Nesse período, como apontou o professor de economia William Easterly (2003) da New York University, enquanto o volume de doações subia ano a ano, o PIB per capta caía. No ano de 1995 o volume de doações atingiu o pico e o PIB per capta o vale, ou seja, o volume de doações foi inversamente proporcional ao crescimento econômico.

O gráfico 1 mostra claramente que quanto maiores as doações (aids percentage of GDP) menor o crecimento econômico (growth per capita). O GDP (Gross Domestic Product) significa PIB - Produto Interno Bruto. Deixando de lado a terminologia econômica e os termos em inglês, o que a figura mostra claramente é que quanto mais assistencialismo (doações) menor foi o desenvolvimento das nações que recebiam a ajuda. 


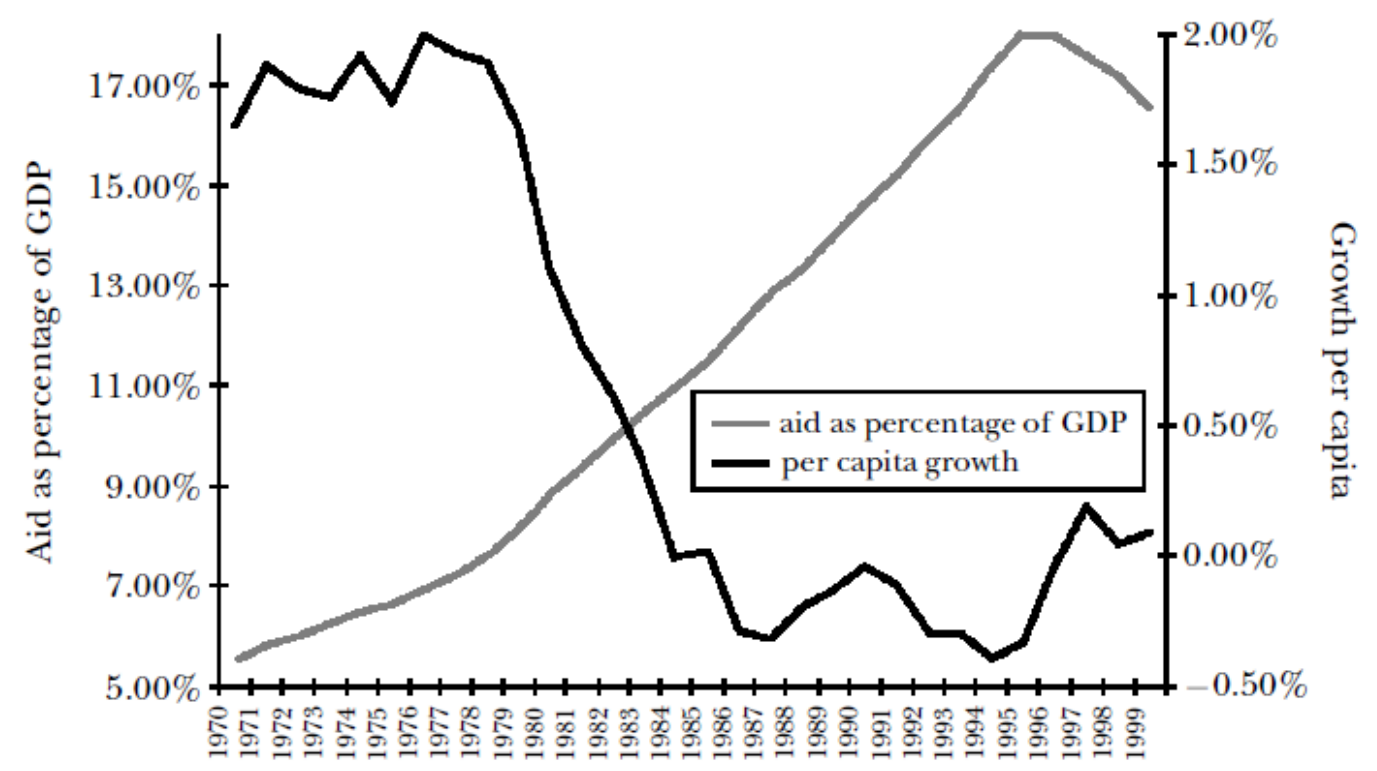

Gráfico 1: Crescimento Econômico X Doações

Fonte: EASTERLY, 2003, p. 35.

Dessa forma, é possível concluir que o empreendedorismo é a única maneira viável e sustentável de tirar comunidades e nações inteiras da miséria e da pobreza. É preciso nos conscientizar que a única maneira real de ajudarmos os outros não é por meio de doações e assistencialismo, mas permitindo às próprias pessoas a se ajudarem, ou seja, liberar o potencial empreendedor presente em todo ser humano. Às vezes, toda a diferença está em apenas emprestar 27 dólares e cobrar de volta, para que as pessoas comercializem entre si, como descobriu Yunnus (2008).

O grande problema é que o paradigma atual nos leva a crer que as pessoas estão lá porque querem ou porque não têm capacidade, uma visão muito fomentada pela mídia de uma forma geral. Mas esta é uma grande inverdade, tanto que quando as pessoas têm oportunidades iguais, nos surpreendemos com as histórias de sucesso que consideramos exceção, quando deveriam ser a regra. Voltando ao exemplo da África, no conjunto, são os países que mais recebem doações, os que menos contribuem com o comércio internacional e os que mais sofrem com a pobreza.

Há várias hipóteses que podem explicar porque esmola não ajuda, porque a caridade não é eficaz para trasnformar a economia e só o empreendedorismo pode 
desenvolver países, como parece que já se convenceu a China, país que mesmo sendo comunista, está se rendendo à livre iniciativa e estimulando o empreendedorismo com ótimos resultados, visíveis a todos.

De fato, quem recebe ajuda graciosamente, fica dependente, perde autoestima, autoconfiança, o foco, se sujeita e se humilha a qualquer condição que lhe é imposta, enfim, perde totalmente o controle de sua vida ao perder a responsabilidade por seu destino e colocar sua salvação nas mãos de quem ajuda.

Além disso, a doação, ao contrário do empreendedorismo com responsabilidade social, não cria empregos, não gera riquezas, não paga impostos, ou seja, funciona como uma droga viciante, quanto mais alguém recebe mais precisa e menos força tem para se livrar dela, destruindo completamente a integridade e a dignidade da pessoa, pois ela perde a fé em si mesma.

Sen (2000, p. 113) afirma que quanto "mais incluso for o alcance da educação básica e dos serviços de saúde, maior será a probabilidade de que mesmo os potencialmente pobres tenham uma chance maior de superar a penúria”.

De fato, o talento só precisa de condições justas para aparecer. Se não conhece o caso, convido o leitor a visitar o site do Instituto Baccarelli criado pelo maestro Sílvio Baccarelli e conhecer histórias inspiradoras, de pessoas que tendo oportunidades iguais se tornaram grandes músicos, alguns até com carreira internacional, trazendo fama, riqueza, dinheiro e desenvolvimento para sua comunidade.

\section{CONSIDERAÇÕES FINAIS}

Portanto, a solução de muitos problemas econômicos e sociais está no empreendedorismo, ou seja, em dar às pessoas oportunidades iguais para empreender e resolver os próprios problemas.

Compreender essa questão é fundamental para o desenvolvimento dos países e mesmo para a manutenção da vida em nosso planeta, uma vez que, por princípio, todas as ações de todas as pessoas, em maior ou menor grau, sempre têm algum impacto positivo ou negativo na vida dos demais cidadãos e da coletividade.

Não existe uma fórmula para garantir o sucesso do empreendedor, havendo a necessidade de várias competências, mas com certeza a responsabilidade social é um fator fundamental. Ser um empreendedor responsável significa também cuidar da 
imagem pública, manter negócios transparentes e relações sociais e profissionais somente com pessoas e organizações idôneas.

Ironia à parte, o exemplo de Porter, um dos gurus mais respeitados no mundo acadêmico, é digno de nota, pois ele, ao que tudo indica, não conseguiu aplicar as recomendações que pregava. Infelizmente a realidade no mundo globalizado é bem essa mesma, a quase totalidade das pessoas concorda que responsabilidade social é crucial para o sucesso e sustentabilidade dos negócios, mas na prática privada, procuram fugir da verdade que eles próprios defendem publicamente.

Por isso, Peter Drucker (2008) defendia a necessidade de o empreendedor refletir sobre as questões mais básicas que impulsionam qualquer negócio, qualquer que seja ele ou qualquer que seja o local onde está localizado: missão, visão, cliente, resultados, planejamento.

É preciso entender que dificilmente há solução para os problemas complexos que a humanidade enfrenta atualmente sem trabalho e inovação, ou seja, empreendedorismo e não apenas assistencialismo.

\section{REFERÊNCIAS}

AYITTEY, George B. N. Africa Betrayed. New York: St Martin’s Press, 1992.

BARROS NETO, João Pinheiro de; SOUZA, Gerson de. Manual do empreendedor: de micro a pequenas empresas. Rio de Janeiro: Qualitymark, 2012.

BUCKINGHAM, Marcus \& CLINTON, Donald O. Descubra seus pontos fortes. São Paulo: Sextante, 2006.

CHARAM, Ram \& BOSSIDY, Larry. Execução: a disciplina para atingir resultados. Rio de Janeiro: Elsevier, 2005.

DIAMANDIS, Peter; KOTLER, Steven. Abundance. New York: Simon \& Schuster, 2012.

DRUCKER, Peter F. Inovação e espírito empreendedor: prática e princípios. São Paulo: Cegange Learning, 2008.

EASTERLY, William. Can foreign aid buy growth? Journal of Economic Perspectives. Volume 17, Number 3. Pittsburgh, PA: AEA Publications, Summer 2003 (p. 23-48). Disponível em <http://docserver.ingentaconnect.com/deliver/connect/aea/08953309/v17n3/s2.pdf?expi 
res $=1356360239 \& \mathrm{id}=72137110 \&$ titleid $=6117 \&$ accname $=$ Guest + User $\&$ checksum $=385$ 4040BFBE0D1695239B9431EFA8F56> Acesso em 24 dez. 2012.

GIL, Antonio Carlos. Como elaborar projetos de pesquisa. 4. ed. São Paulo: Atlas, 2002.

HOUAISS, Antonio. Dicionário Houaiss da língua portuguesa. São Paulo: Objetiva, 2009.

KOTLER, Philip \& LEE, Nancy. Corporate social responsibility: doing the most good for your company and your cause. Hoboken/New Jersey: John Wiley \& Sons, 2005.

MASLOW, Abraham Harold. Motivation and personality. New York: Harper, 1954.

MCCARTY, Dawn; PETTERSSON, Edvard. Monitor Company Group LP files for bankruptcy in Delaware. Disponível em <http://www.bloomberg.com/news/2012-1108/monitor-company-group-lp-files-for-bankruptcy-in-delaware.html> Acesso em 09 nov. 2012.

MOURÃO, Mara. Quem se importa. DVD. São Paulo: Imovision, 2011.

PRAHALAD, C. L. A riqueza na base da pirâmide: erradicando a pobreza com o lucro. Porto Alegre: Bookman, 2010.

ROBINSON, Ken. O elemento-chave. Rio de Janeiro: Ediouro, 2010.

SEN, Amartya. Desenvolvimento como liberdade. São Paulo: Companhia das Letras, 2000 .

STANLEY, Chris. Vocês já emergiram: entrevista exclusiva com Linda Rottenberg. HSM Management. São Paulo: HSM do Brasil, novembro/dezembro 2012 (p. 48-59).

YUNNUS, Muhammad. Um mundo sem pobreza: a empresa social e o futuro do capitalismo. São Paulo: Ática, 2008.

WORLD BANK GROUP. World Development Indicators. USA. <http://data.worldbank.org/data-catalog/world-development-indicators> Acesso em 01 dez. 2012.

WORLD ECONOMIC FORUM. Global Entrepreneurship and the Successful Growth Strategies of Early-Stage Companies. USA: World Economic Forum, 2011. Disponível em <http://www3.weforum.org/docs/WEF_Entrepreneurship_Report_2011.pdf> Acesso em 01 dez. 2012. 